more, on p. 572 we read that "collisions between galaxies are very noisy in the radio wave band", though elsowhere (p. 547) it is correctly stated that the whole theory of colliding galaxies has now fallen out of favour. The whole of the section dealing with artificial satellites and interplanetary probes is out of date, and it would have been wiser to make it complete up to the latest possible date (presumably 1962 or 1963 ) and explain why subsequent developments could not be included.

However, these shortcomings are very minor when the book is considered as a whole, and it would be most unfair to place undue emphasis on them. On balance, this is certainly the best book of its type to have been produced in English during the past quarter of a century, and it will undoubtedly run to many editions. Revisions can bo made from time to time, but the bulk of the text. will need no drastic amendment for some yoars, except in the unlikely event of some spectacular discovery which overturns many theories which have become thoroughly established. All those who have been concerned in the production deserve the highest congratulations, and it is to be hoped that the book will have a wide circulation. Patrick Moore

\section{CRYOGENIC PROCESSES IN GEOLOGY}

\section{An Introduction to the Theory of the Formation of Frozen Rocks}

By I. A. Tyutyunov. Translated from the Russian by J. O. H. Muhlhaus. (International Series of Monographs on Earth Sciences, Vol. 6.) Pp. xiv + 94. (Oxford, London, New York and Paris: Pergamon Press, 1964.) $50 \mathrm{~s}$.

\footnotetext{
T
}

HIS most welcome and fascinating book is the first to describe the physical and chemical changes that occur in regions of permafrost. Although active permafrost research is a restricted investigation, the contents of this book should arouse widespread interest in the more general fields of rock weathering, erosion, soil formation and clay mineralogy. The translation from the original Russian text has been ably carried out, although some passages appear to bo rather unwieldy.

The main theme throughout the book is concerned with the energy that can be liborated by water during sequonces of freezing and thawing and how, as a result, minerals covered by films of water are vigorously attacked. Pcrmafrost investigations are covered by the field of cryogeny which is concerned with the complex physical, chemical and mineralogical changes in the upper strata of the lithosphere and hydrosphere at a nogative geothermal level of heat exchange. The liberation of energy is described in terms of crystal fragmentation by water resulting in a tremendous increaso in potential energy at the water surface layer. The rate and efficiency of conversion of energy in terms of mineral alteration in areas of permafrost are related to the degree of condensation of the potential surface energy and to the concentration of substances (cations, anions) in reactions at such locations. The site where energy changes occur at the water/mineral surface interface is referred to as the 'double surface layer'. The changes involved are dealt with in detail and the formation of cryogenic minerals is described, such as those formed by interaction of $\mathrm{Na}, \mathrm{K}, \mathrm{Mg}$ with $\mathrm{Cl}$, $\mathrm{SO}_{4}$. Through the process of freezing, water provides a significant agency for influencing the concentration and nature of solute present in terrestrial water.

The power of pellicular water in terms of potential energy and penetration is considered to parallel the forces of tectonic processes and is ranked as an outstanding geological factor that must be seriously considered in such environments. Changes concomitant with freezing are described as differentiation processes, and essentially result from dehydration and coagulation of colloids during freezing. The stronger the coagulation of sus. pended material in the soils the groater the result in the progressive increase in the segregation of ice, to such an extent that ice schlieren are formed-a cryogenic texture.

The book introduces various physical and chemical theories in simple terms and develops them to an advanced state. Although the salient points of permafrost. investigations are outlined, geologists would perhaps welcome a more detailed account, particularly as this is the only book on the subject. Also a further chapter describing the practical effect of physical and chemical processes that occur in frozen rocks would be useful for mining and construction engineers.

Permafrost investigations are a rather specialized field of research; however, the approaches and conclusions discussed in this book will undoubtedly be welcomed by those interested in earth sciences.

F. J. Hamilton

\section{HANDBOOK OF ELECTROPLATING}

\section{Handbook of Industrial Electroplating}

By E. A. Ollard and E. B. Smith. Third edition. Pp. $x+400$. (London: Iliffe Books, Ltd.; New York: American Elsevier Publishing Company, Inc., 1964.) $65 s$.

IN their foreword Messrs. Ollard and Smith disclaim any attempt to produce a text-book, and the title happily defines their work as a Handbook of Industrial Electroplating and this it indisputably and most excellently is. No one, accustomed to the problems that arise daily in a modern plating shop and who has studied this book, can fail to believe that a copy of it is an essential item in the personal equipment of every plating shop manager.

Excellence in commercial electrodoposition, to a greater degree perhaps than in most crafts, depends on infinite capacity for taking care, and omphasis on this fact runs like a thread of gold through the whole book. It is certain that the reader who specializes in any section of the vast field covered by the authors will be stimulated to scek out and understand the theories which have contributed so much to the present rapid development of knowledge in this field. Such stimulation alone is rich reward for the possession and study of this book.

This constant need for care in the managoment of a modern electroplating shop is underlined by the fact that the authors have, with great insight, dovoted more than ono quarter of the actual reading matter to testing both depositing solutions and the doposits themselves. For some, these pages will themselves be of absorbing interest and for others an invaluable source of reference.

The growing body of regulation covering industrial effluent disposal fully justifies the attention the authors have devoted to this subject. None whose duty it may be to "design, crect or run" plating plants can afford to ignore the information on this aspect that is so readably set out in this book.

The references to, and information about, automatic and semi-automatic plants whet the appetite for more, and it is to be hoped that in later editions the authors will devote a full chapter to this aspect of plating-shop equipment. Much of the success or failure of operating platers depends on the human factor, and the advent of the completely automated plant must be the droam of many a plating-shop manager.

For many, the most valuable section is that devoted to costing and organization, especially the paragraph on ostimating and the very valuable statistics on productivity. It is to be hoped that future editions will continuously bring these statistics up to date and will amplify them with some indication of the relationship between productivity and the percentage of installed vat time actually used in the period the statistics cover. Those interested in national productivity. and curious as to 